\title{
La Muse et le Compas: poétiques à l'aube de l'âge moderne, édition dirigée par Jean-Charles Monferran
}

Alessandro Turbil

\section{CpenEdition}

Journals

\section{Edizione digitale}

URL: http://journals.openedition.org/studifrancesi/4318

DOI: 10.4000/studifrancesi.4318

ISSN: 2421-5856

\section{Editore}

Rosenberg \& Sellier

\section{Edizione cartacea}

Data di pubblicazione: 1 settembre 2016

Paginazione: $310-311$

ISSN: 0039-2944

\section{Notizia bibliografica digitale}

Alessandro Turbil, «La Muse et le Compas: poétiques à l'aube de l'âge moderne, édition dirigée par JeanCharles Monferran », Studi Francesi [Online], 179 (LX | II) | 2016, online dal 01 septembre 2016 consultato il 18 septembre 2020. URL : http://journals.openedition.org/studifrancesi/4318; DOI : https://doi.org/10.4000/studifrancesi.4318

Questo documento è stato generato automaticamente il 18 settembre 2020.

\section{cc)}

Studi Francesi è distribuita con Licenza Creative Commons Attribuzione - Non commerciale - Non opere derivate 4.0 Internazionale. 


\title{
La Muse et le Compas: poétiques à l'aube de l'âge moderne, édition dirigée par Jean-Charles Monferran
}

\author{
Alessandro Turbil
}

\section{NOTIZIA}

La Muse et le Compas: poétiques à l'aube de l'âge moderne, édition dirigée par Jean-Charles MONFERRAN, Paris, Classiques Garnier, 2015, «Textes de la Renaissance» 196, 370 pp.

1 Il volume curato da Jean-Charles Monferran riunisce i testi di tre arti poetiche databili all'ultimo terzo del Quattrocento (l'Instructif de la seconde rhétorique, l'Art de rhétorique di Jean Molinet e un Traité de rhétorique ou Art de rhétorique pour rimer en plusieurs sortes de rimes), le quali godettero di una certa fortuna per tutto il primo terzo del Cinquecento; i tratti che le accomunano sono la difesa della poesia volgare, l'ambizione alla sua legittimazione attraverso la definizione di modelli - dal Roman de la Rose a Alain Chartier - e il controllo della forma fondata sul virtuosismo. Il contributo scientifico di Guillaume Berthon, Emmanuel Buron, Philippe Frieden, Olivier Halévy, Nicolas Lombart, Jean-Claude Mühlethaler per il lavoro di edizione di queste tre arti poetiche è anticipato, per ogni sezione, da un'introduzione dettagliata e da una bibliografia di riferimento.

2 La prefazione di Jean-Charles Monferran illustra le ragioni dell'opera e il valore della raccolta. Nel sottolineare l'importanza dei tre trattati, l'A. precisa che il lavoro mira a fornire strumenti per comprendere meglio il processo attraverso il quale si realizza, in Francia, un particolare percorso di riconoscimento della poesia in lingua volgare tra il regno di Luigi XII e quello di Francesco I. La scelta dei tre trattati di retorica che compaiono nel volume è infatti compiuta sulla base di due prospettive: la prima risponde alla volontà di rendere disponibili testi di difficile accesso ma significativi, in quanto furono largamente utilizzati dai poeti del primo Cinquecento e dunque recepiti 
dai loro lettori, nonostante essi abbiano fino ad ora goduto di poca fortuna sia tra $\mathrm{i}$ medievisti che tra i cinquecentisti, secondo l'A. principalmente per via della loro composizione in un'epoca di transizione tra tardo Medioevo e Rinascimento; la seconda prospettiva è il risultato di uno specifico lavoro di analisi volto a identificare quali artes poetriae in lingua francese possono aver contribuito in modo maggiore a conferire alla poesia in lingua volgare quella dignità che progressivamente le viene riconosciuta tra la fine del XV secolo e i primi decenni del XVI secolo; in questi trattati, la riflessione sulla poesia volgare «perd [...] en abstraction ce qu'elle gagne en autonomie et en utilité pratique» (p. 10), poiché non concerne più le questioni legate al rapporto tra la poesia $\mathrm{e}$ le altre artes liberales, ma si applica all'attività versificatoria.

3 Nella prima sezione, dedicata all'Instructif de la seconde rhétorique e curata da E. Buron, $\mathrm{O}$. Halévy, J.- C. Mühlethaler, viene presentato il trattato certamente più completo $\mathrm{e}$ complesso tra quelli inseriti nella raccolta. L'introduzione pone attenzione sia alla tradizione manoscritta sia alla diffusione a stampa del testo, che viene edito criticamente basandosi sull'edizione di Antoine Vérard apparsa a Parigi intorno al 1501 (BnF, Réserve Ye 168). In seguito a una disamina delle ipotesi per identificare l'autore del trattato, vengono proposte alcune piste d'identificazione originali sulla base di elementi presenti nel testo. La figura che si delinea è quella di un chierico che intratteneva rapporti con l'ambiente curiale angioino, buon conoscitore della scena letteraria dell'epoca e la cui erudizione presenta sfumature di filosofia scolastica. Per la data di composizione del trattato, gli studiosi propongono come terminus post quem la seconda metà degli anni sessanta del Quattrocento, mentre l'area geografica di origine è identificata con il Nord-Est della Francia, sulla base dei tratti linguistici piccardi. Un'ampia parte dell'introduzione è poi dedicata all'analisi del progetto sotteso alla strutturazione dell'opera e al suo contenuto, con una particolare attenzione per alcuni aspetti quali i presupposti pedagogici, la scelta innovativa della forma in versi, la creatività terminologica dell'autore, le ipotesi sull'origine dei testi citati antologicamente al fine di illustrare i procedimenti poetici descritti. Seguono una breve nota d'edizione, una bibliografia delle edizioni cinquecentesche e una breve bibliografia critica. Un considerevole apparato di note e un glossario, nel quale vengono indicate come di consueto la traduzione, illustrazione o parafrasi in francese moderno del termine e le sue occorrenze, concludono la sezione.

4 La seconda sezione è dedicata all'Art de Rhétorique di Jean Molinet. L'edizione critica, che si basa sul manoscritto BnF, f. fr. 2159, è a cura di G. Berthon e P. Frieden. Il testo, redatto verosimilmente tra il 1482 e il 1493, è presentato dedicando particolare attenzione alle informazioni che i testimoni conosciuti possono fornire in termini di datazione, provenienza e milieux culturali a cui quegli esemplari sembrano rimandare. L'ultima parte dell'introduzione a questo secondo trattato è occupata da uno studio sintetico del testo di questo illustre rhétoriqueur. Chiudono l'introduzione una nota d'edizione, una ricca bibliografia riguardante la tradizione manoscritta e a stampa e gli studi critici. Anche questa edizione è accompagnata da un apparato di note molto dettagliato e da un glossario.

5 La terza e ultima sezione è a cura di N. Lombart e si apre con una breve introduzione all'anonimo Traité de rhéthorique, edito sulla base del manoscritto BnF, f. fr. 2375 che è databile agli inizi del xvi secolo. Per quanto sintetica, è qui più dettagliata che nelle altre introduzioni l'analisi dei tratti linguistici (assai più evidenti nella versione manoscritta, ma conservatisi anche nella versione a stampa) che serve allo studioso per 
attribuire un'area di origine al testo. Dopo aver chiarito il rapporto di filiazione di questo trattato con l'Art de Rhétorique di Molinet, ne vengono studiate le caratteristiche testuali. Note e glossario sono completati qui anche da un indice dei principali titoli e nomi propri.

6 Il volume si chiude con una bibliografia critica e delle fonti citate, un indice del lessico meta-letterario, un indice generale dei nomi propri, dei titoli e dei luoghi. 